\title{
KONTRIBUSI TENAGA KERJA PEREMPUAN TERHADAP PENDAPATAN KELUARGA PADA UD MANDIRI DESA PANGU KECAMATAN RATAHAN TIMUR
}

\author{
Sifora Susan Agouw \\ Tommy F. Lolowang \\ Vicky R. B. Moniaga
}

\begin{abstract}
This study aims to see how much does working women's contribution to family income. The research located in Pangu Village, East Ratahan Sub-district. This research was conducted in April until June 2017. The research used primary and secondary data. Primary data were collected by direct interview technique on 6 (Six) respondents. They are Women Workers who work in UD MANDIRI as dodol and sugar palm wrapper. Secondary data used written data in the form of documents in the Village Office obtained from the village head. Primary data were analyzed used descriptive analysis and presented in tabular form. The results showed that the average income of women worker amounted to Rp.500.000, - in 1 (one) month. The contribution of female labor to family income was $28 \%$ in 1 (one) month.*eprm*.
\end{abstract}

Keywords: contribution, female worker, family income, UD Mandiri, Pangu Village, East Ratahan Sub-district.

\section{ABSTRAK}

Penelitian ini bertujuan untuk melihat seberapa besar kontribusi Tenaga Kerja Perempuan UD MANDIRI terhadap pendapatan keluarga di Desa Pangu, Kecamatan Ratahan Timur. Penelitian ini dilaksanakan pada bulan April sampai dengan bulan Juni 2017. Data yang digunakan adalah data primer dan data sekunder. Data primer dikumpulkan dengan teknik wawancara langsung pada 6 (Enam) orang responden. Mereka adalah Tenaga Kerja Perempuan yang bekerja di UD MANDIRI sebagai pembungkus dodol dan gula aren. Data sekunder menggunakan data tertulis dalam bentuk dokumen di Kantor Desa yang diperoleh dari kepala desa. Data primer dianalisis menggunakan analisis deskriptif dan disajikan dalam bentuk tabel. Hasil penelitian menunjukkan bahwa rata-rata pendapatan perempuan sebesar Rp.500.000,- dalam 1 (satu) bulan. Sedangkan kontribusi pendapatan tenaga kerja perempuan terhadap pendapatan keluarga sebesar $28 \%$ dalam 1 (satu) bulan.*eprm*.

Kata kunci: kontribusi, tenaga kerja perempuan, pendapatan keluarga, UD Mandiri, Desa Pangu, Kecamatan Ratahan Timur.

\section{PENDAHULUAN}

\section{Latar Belakang}

Perempuan Indonesia terutama di pedesaan adalah sebagai sumber daya manusia yang cukup nyata berpartisipasi khususnya dalam memenuhi fungsi ekonomi keluarga dan rumah tangga bersama laki-laki. Partisipasi tenaga kerja perempuan memang erat kaitannya dengan latar belakang keluarga, mengingat bahwa fungsi keluarga dalam pengambilan keputusan sangat menentukan. Kemiskinan yang dihadapi oleh sebagian besar keluarga di pedesaan menuntut keikutsertaan semua anggota keluarga untuk memikirkannya (Praditya dan Maryunianta, 2014).

Dalam rangka dinamika dan pergeseran mata pencaharian daerah pedesaan yang cenderung berubah pola agraris ke non-agraris, misalnya menonjolkan aktivitas industri rumah tangga, industri pariwisata, jasa, kehidupan sektor formal lainnya seperti pendidikan, 
pegawai, dan lain sebagainya, ternyata perempuan memegang peranan juga. Terutama untuk menambah pendapatan keluarga dan membantu kegiatan suami serta mengurangi beban dan ketergantungan istri terhadap suami (Kartini, 1995).

Keterlibatan perempuan dalam kerja produktif akan menimbulkan perubahan sosial, di karenakan salah satu wujud perubahan sosial adalah perubahan dalam kerja. Masuknya perempuan dalam pasar kerja produktif berpengaruh terhadap kegiatan ekonomi rumah tangga sehingga dapat terjadi perubahan struktur ekonomi keluarga (Wisadirana, 2004).

Bekerja adalah melakukan kegiatan yang bertujuan untuk memperoleh pendapatan atau penghasilan. Presentase laki-laki yang bekerja lebih beser dari pada perempuan, disebabkan laki-laki adalah kepalah rumahtangga, sebaliknya perempuan pada umunya bukan pencari nafkah, tetapi fungsinya lebih kepada penambahan pendapatan suami (BPS, 1992).

Sebagian besar perempuan di Indonesia berupaya menutupi kekurangan kebutuhan keluarga di sebabkan penghasilan suami yang kecil dan cenderung tidak menentu. Kebutuhan sehari-hari yang merupakan kebutuhan pokok seperti makanan dan transport sekolah haruslah di atur sedemikian rupa supaya tidak melebihi penghasilan perempuan yang di dapatnya setiap harinya (Ari, dkk 2000).

Citra perempuan pada aspek sosial di sederhanakan dalam dua peran, yaitu peran perempuan dalam keluarga dan peran perempuan dalam masyarakat. Peran perempuan dalam keluarga apakah sebagai istri, sebagai ibu, dan sebagai pengurus rumahtangga, dimana memiliki tugas mendampingi suami, memasak, mendidik anak-anak dan mengurus rumahtangga seperti melakukan bersih-bersih rumah, memasak, dan lain-lain. Peran perempuan dalam masyarakat yaitu di hubungkan dengan kegiatan sosial sesuai dengan yang ada dalam masyarakat terdiri dari kegiatan gotong royong, arisan, dan lain-lain.

Setiap usaha pertanian yang dilaksanakan memerlukan tenaga kerja. Oleh karena itu di dalam analisis ketenagakerjaan dibidang pertanian, penggunaan tenaga kerja yang dinyatakan oleh besarnya curahan tenaga kerja efektif yang dipakai. Curahan kerja adalah waktu yang dialokasikan untuk melakukan serangkaian kegiatan yang bisa dilakukan di dalam dan di luar rumahtangga dalam satuan waktu atau jam (Sunarjo, 1997).

Adanya kegiatan seorang perempuan mencari nafkah dalam meningkatkan kontribusi pendapatan dalam memenuhi kebutuhan seharihari keluarganya. Dimana-mana perempuan hanya aktif sebagai ibu rumahtangga yang mengurus suami dan anak. Akan tetapi, fakta di luar lapangan menunjukan bahwa perempuan sangat berperan aktif berperan di luar rumah. Hal ini disebabkan karena rendahnya pendapatan suami dalam bekerja, tentu memacu perempuan juga berkontribusi dalam mencari nafkah agar kebutuhan keluarga terpenuhi.

Perkembangan agroindustri sebagai sarana pembangunan telah mengalami peningkatan yang cukup tinggi dalam kesempatan kerja. Hal ini menunjukkan bahwa agroindustri semakin efektif sebagai penggerak pembangunan ekonomi yang didukung oleh kemampuan teknologi dalam pemanfaatan sumber daya yang optimal serta meningkatkan peran serta masyarakat secara produktif dan meluasnya penyebaran lokasi agroindustri di daerah-daerah. Adanya kerja sama yang baik antara sektor pertanian dan agroindustri menciptakan suatu bentuk kegiatan usaha pengolahan hasil pertanian yang merupakan konsep dari agribisnis. Menurut Arsyad dkk cit Soekartawi (2003), konsep dari agribisnis yang sebenarnya adalah suatu kegiatan yang meliputi salah satu atau keseluruhan dari mana rantai produksi. Di Indonesia banyak terdapat usaha agroindustri, salah satunya adalah di UD. MANDIRI ini memproduksi olahan makanan da antaranya, dodol salak dan gula aren.

Peningkatan kesempatan kerja di sektor agroindustri bukan saja penting bagi laju pertumbuhan ekonomi karena produktifitas tenaga kerja naik dan kenaikan lebih cepat terjadi di sektor agroindustri. Dalam keluarga miskin pada umumnya seluruh sumber daya manusia dikerahkan untuk memperoleh penghasilan sebagai upah pemenuhan kebutuhan sehari-hari. Peran aktif perempuan dalam peningkatan pendapatan mereka bersedia melakukan pekerjaan apapun, terutama sektor 
informal yang tidak memiliki keahlian khusus, mudah di masuki, dan tidak membutuhkan modal besar. Berkaitan dengan pengerahan sumber daya ekonomi yang di miliki rumahtangga miskin, maka di tuntut perempuan sebagai istri untuk menopang ketahanan ekonomi keluarga. Kondisi demikian merupakan dorongan yang kuat bagi perempuan untuk bekerja diluar rumah. Dalam beberapa tahun terahir ini keterlibatan perempuan pada sektor publik menunjukan angka yang terus meningkat. Perempuan pada rumah tangga miskin, rata-rata mempunyai tingkat pendidikan yang relatifrendah karena kondisi ekonomi yang melatarbelakanginya. Perempuan dengan tingkat pendidikan yang rendah dan keterampilan juga rendah inilah yang justru banyak masuk ke lapangan kerja terutama pada sektor informa dan motivasi menambah pendapatan keluarga.

Desa Pagu Kecamatan Ratahan Timur merupakan salah satu desa di Kabupaten Minahasa Tenggara yang memiliki industri rumahtangga yaitu UD MANDIRI yang mengusahakan agroindustri dodol salak, gula semut, kopi kobisa. Tenaga kerja yang diserap adalah 6 tenaga kerja laki-laki dan 6 tenaga kerja perempuan. Tenaga kerja perempuan bekerja pada industri ini karena adanya tuntutan pemenuhan kebutuhan ekonomi dalam rumahtangga. Adanya agroindustri UD MANDIRI ini selain dapat memberikan penghasilan bagi tenaga kerja yang ada, terlebihih tenaga kerja perempuan dapat mengaktualisasi diri tanpa harus meninggalkan tanggung jawab mereka sebagai ibu rumahtangga. Keadaan ini yang mendorong penelitian mengenai partisipasi dan kontribusi tenaga kerja perempuan pada agroindustri UD MANDIRI di Desa Pangu Kecamatan Ratahan Timur Kabupaten Minahasa Tenggara.

UD. MANDIRI adalah usaha kecil dan menengah yang di dirikan oleh Bpk. Artje Sengkey, pada tahun 2006 yang merupakan badan usaha yang bergerak dalam produksi camilan khas Kabupaten Minahasa Tenggara, seperti dodol salak dan gula aren. Dua camilan ini sudah didistribusikan di Kota Manado, Tomohon, Tondano, dan kota-kota lain disekitaran Sulawesi Utara.

\section{Rumusan Masalah}

Berdasarkan latar belakang di atas maka, yang jadi perumusan masalah dalam penelitian ini adalah:

1. Berapa besar curahan tenaga kerja perempuan pada UD MANDIRI ?

2. Berapa besar pendapatan yang diperoleh tenaga kerja perempuan yang bekerja di UD MANDIRI ?

3. Berapa besar kontribusi tenaga kerja perempuan terhadap pendapatan keluarga?

\section{Tujuan Penelitian}

1. Untuk menentukan curahan tenaga kerja perempuan pada UD MANDIRI ?

2. Untuk menentukan besarnya pendapatan tenaga kerja perempuan pada UD. MANDIRI ?

3. Menganalisis seberapa besar kontribusi tenaga kerja perempuan terhadap pendapatan keluarga?

\section{Manfaat Penelitian}

Manfaat yang diperoleh dalam penelitian ini diharapkan dapat memberikan informasi kepada pembaca tentang UD MANDIRI.

\section{METODE PENELITIAN}

\section{Waktu dan Tempat Penelitian}

Penelitian ini berlangsung selama 3 bulan dari bulan April sampai dengan bulan Juni 2017, mulai dari persiapan sampai dengan penyusunan laporan penelitian. Tempat penelitian di Desa Pangu Kecamatan Ratahan Timur Kabupaten Minahasa Tenggara.

\section{Jenis dan Sumber Data}

Data yang digunakan dalam penelitian ini yaitu data primer, data primer di peroleh dengan melakukan wawancara langsung kepada responden. 


\section{Metode Pengumpulan Data}

Metode pengumpulan data diambil sampel seluruh tenaga kerja perempuan lewat wawancara dan pengamatan (observasi). Pengumpulan data menggunakan kuisioner, dan turun ke lapanganlangsung setelah itu dipilih responden dan disesuaikan dengan pengukuran variabel, untuk melihat kontribusi tenaga kerja perempuan dalam UD. MANDIRI di Desa Pangu Kecamatan Ratahan Timur Kabupaten Minahasa Tenggara. Jumlah sampel adalah sebanyak 6 sampel.

\section{Pengukuran Variabel} ini:

Variabel yang diukur dalam penelitian

1. Karakter responden seperti umur, tingkat pendidikan, jumlah tanggungan dalam keluarga.

2. Kontribusi: besarnya pendapatan perempuan dibandingkan dengan pendapatan keluarga yang dinyatakan dalam presentase.

\section{Analisis Data}

1. Untuk mengitung curahan tenaga kerja perempuan pada agroindustri UD.MANDIRI, denagan perhitungan sederhan untuk menentukan HOK, menurut (Suratiyah, 2009) dengan rumus :

JK Total $=$ JKO $\times$ HKO $\times$ JK

Dimana $: \mathrm{JK}=$ Jam Kerja

$$
\begin{aligned}
\mathrm{JKO} & =\text { Jam Kerja Orang } \\
\mathrm{HKO} & =\text { Hari Kerja Orang }
\end{aligned}
$$

2. Untuk menghitung besarnya pendapatan, menurut (Soekartawi, 2002) menggunakan rumus :

$$
\mathrm{I}=\mathrm{TR}-\mathrm{TC}
$$

Dimana $: \mathrm{I}=$ Pendapatan Bersih (Income)

$\mathrm{TR}=$ Total Penerimaan (total race)

$\mathrm{TC}=$ Total biaya yang dikeluarkan

(total cost)

3. Untuk menghitung besarnya kontribusi tenaga kerja perempuan terhadap pendapatan keluarga, digunakan metode sederhana dengan perhitungan pendapatan dengan menggunakan rumus :
Kontribusi Tenaga Kerja $=\frac{\text { Pendapatan Perempuan }}{\text { Total Pendapatan Keluarga }} \mathrm{X} 100$

\section{HASIL DAN PEMBAHASAN}

\section{Deskripsi Penelitian}

Kabupaten Minahasa Tenggara merupakan wilayah strategis yang merupakan salah satu Kabupaten di Provinsi Sulawesi Utara. Kabupaten ini terletak pada posisi tengah jazirah yang berjarak $\pm 85 \mathrm{~km}$ dari Kota Manado sebagai Ibukota Propinsi Sulawesi Utara. Ibukota Kabupaten Minahasa Tenggara adalah Ratahan yang secara geografis wilayah Kabupaten Minahasa Tenggara terletak pada $124^{\circ} 30^{\prime} 24^{\prime}$ 'BT $124^{\circ} 56^{\prime} 24^{\prime}$ 'BT dan $0^{\circ} 50^{\prime} 46^{\prime}$ 'LU $1^{\circ} 08^{\prime} 19$ ''LU. Luas daratan Kabupaten Minahasa Tenggara mencapai $730,62 \mathrm{~km}^{2}$ dan luas lautan \pm 4 mil $=306,39 \mathrm{~km}^{2}$ dengan panjang pada garis pantai $102 \mathrm{~km}^{2}$.

Sebagian besar kondisi topografi dan geomorfologi wilayah Kabupaten Minahasa Tenggara adalah bergunung-gunung dan berbukit-bukit yang membentang dari Utara ke Selatan. Ketinggian tempat bervariasi antara wilayah yang paling rendah dan yang sejajar permukaan laut, hingga wilayah tertinggi di puncak gunung. Sebagian kecil dataran rendah bergelombang di bagian Selatan dengan posisi dari daerah pantai sampai ketinggian 1300 meter dpl dan di antaranya terdapat gugusan pegunungan Manimporok dan gunung berapi yang masih aktif, yaitu Gunung Api Soputan tinggi $1.784 \mathrm{~m} \mathrm{dpl}$ (5853 feet) terletak di antara perbatasan Kabupaten Minahasa Tenggara dan Kabupaten Minahasa Selatan, serta Kabupaten Minahasa. Desa Pangu ini memiliki penduduk sebesar 1045 jiwa. Adapun batas-batas wilayah Desa Pangu sebagai berikut:

1. Sebelah utara berbatasan dengan wilayah langowan (Kabupaten Minahasa)

2. Sebelah Barat berbatasan dengan perkebunan wongkai.

3. Sebalah Timur berbatasan dengan Desa Wongkai satu.

4. Sebelah Selatan berbatasan dengan Desa Wiau (Kecamatan Posumaen). 


\section{Keadaan Penduduk}

\section{Penduduk Menurut Umur dan Jenis Kelamin}

Penduduk di Desa pangu berjumlah jiwa dengan rincian penduduk laki-laki dan jiwa penduduk perempuan. Untuk lebih jelasnya dapat dilihat dalam Tabel 1.

Tabel 1. Jumlah Penduduk Menurut Kelompok Umur di Desa Pangu Kecamatan Ratahan Timur Tahun 2017

\begin{tabular}{cccc}
\hline No & $\begin{array}{c}\text { Kelompok Umur } \\
\text { (Tahun) }\end{array}$ & $\begin{array}{c}\text { Jumlah penduduk } \\
(\text { Jiwa })\end{array}$ & $\begin{array}{c}\text { Presentase } \\
(\%)\end{array}$ \\
\hline 1 & $0-5$ & 50 & 4,79 \\
2 & $6-10$ & 75 & 7,17 \\
3 & $11-15$ & 50 & 4,79 \\
4 & $16-20$ & 80 & 7,65 \\
5 & $21-25$ & 105 & 10,04 \\
6 & $26-30$ & 107 & 10,23 \\
7 & $31-35$ & 105 & 10,04 \\
8 & $36-40$ & 90 & 8,61 \\
9 & $41-45$ & 80 & 7,65 \\
10 & $46-50$ & 89 & 8,51 \\
11 & $51-55$ & 77 & 7,36 \\
12 & $56-60$ & 70 & 6,69 \\
13 & $>60$ & 67 & 6,47 \\
\hline \multicolumn{5}{c}{} & Jumlah & 1045 & 100 \\
\hline
\end{tabular}

Sumber: Data Desa Pangu 2017

\section{Penduduk Menurut Tingkat Pendidikan}

Tingkat pendidikan formal merupakan salah satu kunci utama dalam membangun dan mengembangkan masyarakat, karena pendidikan merupakan fundamental dasar dalam pembentukkan pola pikir dalam pandangan masyarakat di tengah-tengah lingkungannya. Tingkat pendidikan di Desa Pangu Kecamatan Ratahan Timur dapat dilihat dalam Tabel 2.

Tabel 2. Jumlah Penduduk Menurut Tingkat Pendidikan Formal di Desa Pagu Kecamatan Ratahan Timur Tahun 2017

\begin{tabular}{clcc}
\hline No & Tingkat pendidikan & $\begin{array}{c}\text { Jumlah penduduk } \\
\text { (jiwa) }\end{array}$ & $\begin{array}{c}\text { Presentase } \\
(\%)\end{array}$ \\
\hline 1 & $\begin{array}{l}\text { Belum sekolah dan } \\
\text { tidak tamat SD }\end{array}$ & 175 & 16,04 \\
2 & Tamat SD & 109 & 10,43 \\
3 & Tamat SLTP & 161 & 15,4 \\
4 & Tamat SLTA & 390 & 37,28 \\
5 & Tamat (D1,D2,D3) & 95 & 9,85 \\
6 & Sarjana (S1,S2,S3) & 115 & 11 \\
\hline & $\quad$ Jumlah & 1045 & 100 \\
\hline
\end{tabular}

Sumber: Data Monografi Desa Pangu 2017

Tabel 2 menunjukan bahwa penduduk desa Pangu rata-rata memiliki pendidikan yang tinggi, dimana sebanyak 390 penduduk memiliki tingkat pendidikan SLTA, sedangkan 95 penduduk memiliki pendidikan (D1,D2,D3) dan 115 penduduk memiliki pendidikan S1.

\section{Penduduk Menurut Mata Pencaharian}

Mata pencaharian ataupun jenis pekerjaan penduduk di Desa Pagu, dapat dilihat dalam Tabel 3.

Tabel 3. Jumlah Penduduk Menurut Jenis Mata Pencaharian di Desa Pangu Kecamatan Ratahan Timur Tahun 2017

\begin{tabular}{clcc}
\hline No & Mata Pencaharian & Jumlah (jiwa) & Presentse (\%) \\
\hline 1 & PNS & 126 & 18,52 \\
2 & TNI/POLRI & 12 & 1,76 \\
3 & Tenaga kesehatan & 67 & 9,85 \\
4 & Swasta & 175 & 25,73 \\
5 & Pedagang & 85 & 12,5 \\
6 & Petani & 215 & 31,64 \\
\hline & $\quad$ Jumlah & 680 & 100 \\
\hline
\end{tabular}

Sumber : Data Monografi Desa Pangu 2017

\section{Karakteristik Tenaga Kerja Perempuan}

\section{Umur Responden}

Identitas tenaga kerja perempuan menggambarkan kondisi umum dari tenaga kerja perempuan di UD MANDIRI di Desa Pangu Kecamatan Ratahan Timur Kabupaten Minahasa Tenggara yang bekerja disana meliputi: umur, pendidikan, jumlah tanggungan.

Umur merupakan salah satu faktor yang mempengaruhi perilaku atau dalam mengambil keputusan dan dapat bekerja secara optimal serta produktif. Seiring dengan perkembangan waktu umur manusia akan mengalami perubahan, dalam perubahan usia dapat mengakibatkan turunnya tingkat produktifitas seorang dalam bekerja, dalam tabel dibawah ini dapat dilihat karakteristis responden menurut umur.

Tabel 4. Karakteristik Umur Tenaga Kerja Perempuan pada UD. MANDIRI di Desa Pangu, Kecamatan Ratahan Timur

\begin{tabular}{cccc}
\hline No & Umur (tahun) & Jumlah & $\%$ \\
\hline 1 & $30-40$ & 3 & 50,00 \\
2 & $41-50$ & 2 & 33,34 \\
3 & $51>$ & 1 & 16,66 \\
\hline & Jumlah & 6 & 100 \\
\hline
\end{tabular}

Dari Tabel 4 dapat diketahui umur tenga kerja perempuan yang bekerja di UD MANDIRI Desa Pangu Kecamatan Ratahan Timur, berkisar umur 30 tahun sampai 52 tahun dengan rata-rata pekerja berumur 30 tahun, umur ini masi dalam kategori produktif, sehingga tenaga kerja perempuan mempunyai produktivitas kerja yang cukup tinggi. Lestari et 
al (1997), menyatakan bahwa usia seseorang berkaitan dengan produktivitas dalam bekerja. Apabilah seorang telah mencapai usia lanjut, tenaga untuk bekerja atau mengolah usaha berkurang. Tetapi apabila usia seorang masi dalam usia produktif, maka produktivitasnya dapat ditingkatkan, sehingga hasil pekerjaan yang diperoleh semakin banyak dan pendapatan yang diperoleh semakin bertambah.

\section{Tingkat Pendidikan}

Pendidikan merupakan hal yang sangat penting di dalam kehidupan manusia dan pendidikan itu sendiri akan diperoleh setiap orang secara formal maupun non formal. Dalam Tabel 5 dapat dilihat tingkat pendidikan dari responden.

\begin{tabular}{|c|c|c|c|c|}
\hline Tab & 5. & $\begin{array}{l}\text { Karakteristik } \\
\text { Responden pa } \\
\text { Pangu, Kecam }\end{array}$ & $\begin{array}{l}\text { ngkat Pendidik } \\
\text { UD MANDIRI } \\
\text { Ratahan Timu }\end{array}$ & $\begin{array}{l}\text { dari } \\
\text { Desa }\end{array}$ \\
\hline No & Ting & gkat Pendidikan & Jumlah (orang) & $\%$ \\
\hline 1 & Tidak & k sekolah & - & - \\
\hline 2 & SD & & 1 & 16,66 \\
\hline 3 & SMP & & 1 & 16,66 \\
\hline 4 & SMA & & 4 & 66,68 \\
\hline & & Jumlah & 6 & 100 \\
\hline
\end{tabular}

Hasil wawancara yang didapat menunjukan tingkat pendidikan tenaga kerja perempuan yang bekerja di UD MANDIRI, di antaranya 1 tenaga kerja hanya lulusan SD, 1 tenaga kerja lulusan SMP, sedangkan 4 tenaga kerja menyelesaikan sekolah di bangu SMA. Pendidikan seorang memang berkaitan dengan keputusan untuk bekerja guna memperbaiki taraf hidup yang lebih baik lagi. Di UD MANDIRI tersebut memiliki $66,68 \%$ pekerja dengan tingkat pendidikan yang lulus SMA. Dengan pendidikan tersebut memotifasi para perempuan untuk membantu pendapatan keluarga.

\section{Jumlah Tanggungan Responden dan Alasan Bekerja}

Jumlah yang dimaksud dalam penelitian ini adalah anggota keluarga yang statusnya belum berkeluarga (single) dan masi ditanggung responden. Jumlah keluarga yang ditanggung oleh responden dapat dilihat dalam Tabel 6.

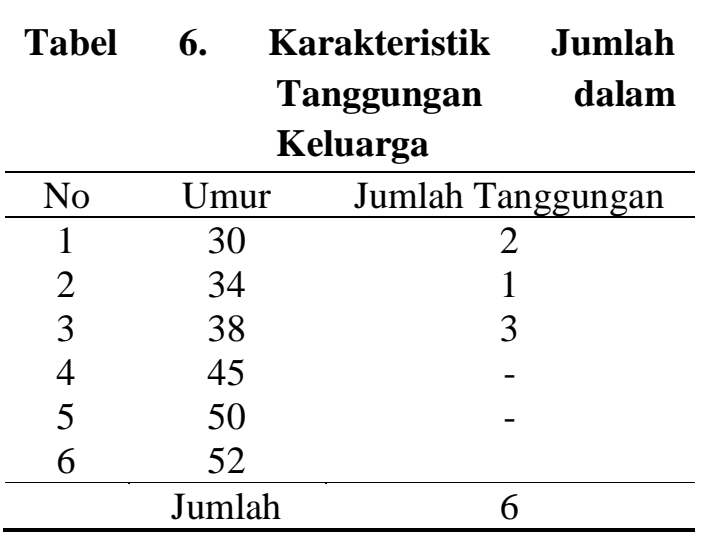

Berdasarkan Tabel 6, dapat dilihat bahwa jumlah tanggungan setiap responden, terlihat umur 30 tahun memiliki 2 orang tanggungan, sedangkan umur 38 tahun memiliki tanggungan 3 orang, jumlah tanggungan ini mendorong responden untuk membantu pendapatan dalam keluarga guna membantu pendapatan dalam keluarga.

\section{Curahan Tenaga Kerja}

Tenaga Kerja merupakan salah satu faktor penentu dalam keberhasilan setiap usaha. Dalam suatu sistem pertanian yang memandang keluarga sebagai unit terkecil dari usaha pertanian, peran keluarga dapat dinilai dari berbagai aspek produktif dan konsumtif. Dalam kedua aspek ini perempuan memiliki tanggung jawab yang khusus bagi berlangsungnya fungsi keluarga. Untuk itu berbagai upaya yang dapat dilakukan oleh perempuan dalam membantu dan memberikan kontribusi yang lebih besar untuk meningkatkan kesejatraan keluarga.

Curahan waktu kerja adalah waktu yang digunakan tenaga kerja untuk bekerja di UD MANDIRI. Berdasarkan hasil wawancara dengan para responden, waktu yang dicurahkan tenaga kerja pada UD MANDIRI ini tidaklah sama, berikut adalah data besarnya curahan tenaga kerja perempuan pada UD MANDIRI.

Tabel 7. Rataan Curahan Tenaga Keja Perempuan di UD MANDIRI Desa Pangu Kecamatan Ratahan Timur

\begin{tabular}{|c|c|c|c|c|}
\hline No & Uraian kegiatan & HKO/ Hari & Jam & $\begin{array}{c}\text { Persen } \\
(\%)\end{array}$ \\
\hline 1 & Mengurus rumahtangga & 0,7 & 7 & 58,44 \\
\hline \multirow[t]{2}{*}{2} & Bekerja di UD MANDIRI & 0,5 & 5 & 41,66 \\
\hline & Total & 1,2 & 12 & 100 \\
\hline
\end{tabular}


Dari Tabel 7 menunjukan bahwa seluruh tenaga kerja perempuan yang bekerja di UD MANDIRI memiliki curahan tenaga kerja yang terbagi yaitu mengurus rumah tangga dan bekerja di UD MANDIRI, dengan waktu kerja mengurus rumah tangga 7 $\mathrm{jam} /$ hari atau 58,44\% dengan HOK 0,7, dan bekerja di UD MANDIRI hanya 5 jam/harinya atau 41,66\% denagn HOK 0,5. Curahan tenga kerja perempuan ini lebih besar pada mengurus rumahtangga dikarenakan seluruh tenaga kerja yang bekerja di tempat penelitian semua sudah berkeluarga. Oleh karena itu adanya pembagian waktu kerja.

\section{Pendapatan Tenaga Kerja}

Pendapatan tenaga kerja perempuan yang diperoleh dari industri kecil UD MANDIRI adalah per harinya di upah sebesar Rp.41.700 dengan waktu kerja 1 minggu 3 hari kerja. Pendapatan perminggunya sebesar Rp.125.100, sedangkan pendapatan tenaga kerja perbulannya Rp.500.000 dari industri kecil UD MANDIRI. Adapun satu tenaga kerja yang memiliki kerja sampingan sebagai pembantu buruh cuci pakaian yang di gaji Rp.250.000 per bulannya.

Tabel 8. Rata-rata Upah Tenaga Kerja Perempuan pada UD MANDIRI dan Pendapatan Tambahan Lainnya (Rp/BIn)

\begin{tabular}{ccc}
\hline No & Uraian PekerjaanPekerjaan & Pendapatan (Rp/Bln) \\
\hline 1 & Bekerja di UD MANDIRI & Rp. 500.000 \\
2 & Pemabantu Rumah Tangga & Rp. 250.000 \\
\hline
\end{tabular}

Dari Tabel 8 dapat dilihat pendapatan tenaga kerja perempuan yang bekerja di UD MANDIRI berpengahasilan sebesar Rp.500.000, sedangkan bekerja menjadi buruh cuci baju mendapatkan upah sebesar Rp.250.000. memang pendapatan yang diterima tenaga kerja perempuan masih sangat kecil, tetapi lewat pendapatan yang kecil ada pemberian bonus disaat hari raya, dengan adanya bonus yang diberikan dapat meningkatkan produktivitas tenaga kerja perempuan yang bekerja di UD MANDIRI.
Pendapatan keluarga dapat diperoleh dari penjumlahan antara pendapatan suami dengan pendapatan istri. Secara sistematis dapat dilihat pada rumus berikut

Pendapatan Keluarga $=$ Pendapatan Suami + Pendapatan Istri

Tabel 9. Total Pendapatan Keluarga

\begin{tabular}{ccc}
\hline No & Uraian & Rata-rata $(\mathrm{Rp} / \mathrm{B} 1 \mathrm{n})$ \\
\hline 1 & Total Pendapatan Suami & Rp. 1.500 .000 \\
2 & Total Pendapatan Istri & Rp. 500.000 \\
\hline & Total pendapatan keluarga & Rp. 2.000 .000 \\
\hline
\end{tabular}

Dari tabel diatas dapat dilihat bahwa ratarata pendapatan tenaga kerja suami sebesar Rp.1.500.000 / bulan dan rata-rata pendapatan istri sebesar Rp.500.000 / bulan, sehingga total pendapatan keluarga berjumlah Rp.2.000.000 / bulan. Berdasarkan total pendapatan keluarga diatas berarti bahwa pendapatan keluarga disini tergolong masi minim, oleh karena itu besarnya keinginan perempuan untuk bekerja untuk membantu pendapatan rumah tangga.

\section{Kontribusi Pendapatan Tenaga Kerja Perempuan Terhadap Pendapatan Keluarga Industri kecil UD MANDIRI merupakan sumber pendapatan bagi penduduk setempat guna untuk memenuhi kebutuhan konsumsi keluarga. Besarnya sumbangan pendapatan tenaga kerja perempuan yang bekerja di UD MANDIRI dapat dihitung menggunakan rumus: \\ Kontribusisi Tenaga Kerja Perempua $=\frac{\text { Pendapatan Perempuan }}{\text { Total Pendapatan Keluarga }} \times 100 \%$}

Besarnya kontribusi pendapatan tenaga kerja perempuan terhadapa total pendapatan rumahtangga dapat dilihat pada Tabel 10.

\begin{tabular}{|c|c|c|c|}
\hline \multicolumn{4}{|c|}{$\begin{array}{l}\text { Tabel 10. Kontribusi Pendapatan Tenaga Kerja Perempuan } \\
\text { Terhadap Toal Pendapatan Keluarga }\end{array}$} \\
\hline No & Uraian & Rata-rata (Rp/Bln) & $\%$ \\
\hline 1 & Total pendapatan suami & 1.500 .000 & 72,00 \\
\hline 2 & Total pendapatan istri & 500.000 & 28,00 \\
\hline & Total pendapatan Keluarga & 2.000 .000 & 100 \\
\hline
\end{tabular}

Dari tabel diatas terlihat bahwa presentase kontribusi pendapatan tenaga kerja laki-laki (suami) terhadap tendapatan keluarga sebesar $72,00 \%$, sedangkan presentase kontribusi pendapatan perempuan terhadap total pendapatan keluarga sebesar $28,00 \%$. hal ini 
berarti bahwa kontribusi pendapatan perempuan terhadap pendapatan keluarga masi sangat kecil. Kontribusi pendapatan tenaga kerja perempuan rendah dikarenakan upah yang diberikan oleh pengusaha industri kecil memang masi sangat rendah, dengan curahan waktu yang dicurahkan pun masih sangat sedikit, dan jenis pekerjaan yang dikerjakan pada industri tersebut juga sangatlah mudah, hanya membungkus dodol dan gula aren saja. Di bandingkan dengan pendapatan suami yang umumnya mempunyai kontribusi yang sangat besar didalam pendapatan keluarga, dikarenakan suami mempunyai kewajiban mencari nafkah.

\section{KESIMPULAN DAN SARAN}

\section{Kesimpulan}

1. Curahan tenaga kerja perempuan yang bekerja di UD MANDIRI yakni 5 jam perharinya. Sedangkan mengurus rumah tangga 7 jam/hari.

2. Pendapatan yang diperoleh tenaga kerja perempuan yaitu rata-rata sebesar Rp.500.000 / bulannya.

3. Kontribusi pendapatan tenaga kerja perempuan pada UD MANDIRI terhadap pendapatan keluarga yakni sebesar $28 \%$.

\section{Saran}

Adapun saran yang bisa diajukan adalah kepada pengusaha, diharapkan pengusaha dapat memperhatikan upah tenaga kerja yang di berikan kepada pekerja, harapannya pekerja dapat menerima upah yang lebih banyak untuk menopang kebutuhan keluarga.

\section{DAFTAR PUSTAKA}

Praditya, Y., \& Maryunianta, I. 2014. Peranan Tenaga Kerja Wanita pada Pemasaran Dodol Serta Kontribusinya terhadap Pendapatan Keluarga di Desa Bengkel Kecamatan Perbaungan Kabupaten Serdang Bedagai. Journal of Agriculture and Agribusiness Socioeconomics, 3(6).
Kartini, S. 1995. Wanita Indonesia. Jakarta, Majalah Kartini edisi dua mingguan.

Sunarjo, H. 1997. Prospek Berkebun Buah. Penebar Swadaya, Jakarta. 